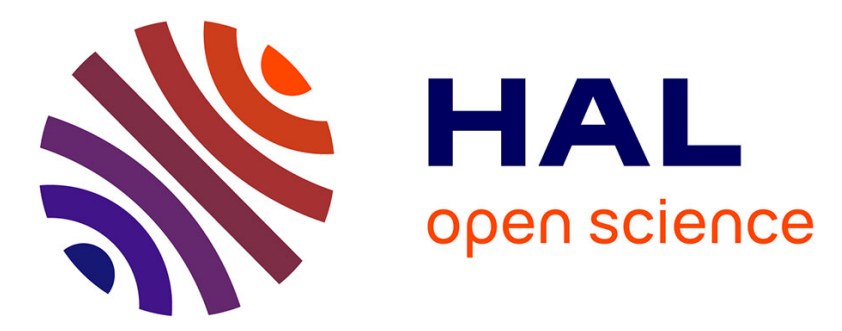

\title{
Connecting the strategic intent of innovation labs and projects: the case of the Green Fablab
}

Thibaut Roux-Marchand, Fabio Cruz, Laurent Dupont, Mauricio Camargo, Ferney Osorio

\section{- To cite this version:}

Thibaut Roux-Marchand, Fabio Cruz, Laurent Dupont, Mauricio Camargo, Ferney Osorio. Connecting the strategic intent of innovation labs and projects: the case of the Green Fablab. 2020 IEEE International Conference on Engineering, Technology and Innovation (ICE/ITMC), Jun 2020, Cardiff, United Kingdom. 10.1109/ICE/ITMC49519.2020.9198320 . hal-02941900

\author{
HAL Id: hal-02941900 \\ https://hal.science/hal-02941900
}

Submitted on 17 Sep 2020

HAL is a multi-disciplinary open access archive for the deposit and dissemination of scientific research documents, whether they are published or not. The documents may come from teaching and research institutions in France or abroad, or from public or private research centers.
L'archive ouverte pluridisciplinaire HAL, est destinée au dépôt et à la diffusion de documents scientifiques de niveau recherche, publiés ou non, émanant des établissements d'enseignement et de recherche français ou étrangers, des laboratoires publics ou privés. 


\section{Connecting the strategic intent of innovation labs and projects: the case of the Green Fablab}

\author{
Thibaut Roux-Marchand \\ CESI LINEACT \\ Nancy, France \\ trouxmarchand@cesi.fr
}

\author{
Fabio Cruz \\ Université de Lorraine \\ ERPI \\ F-54000 Nancy, France \\ cruzsanc1@univ-lorraine.fr
}

\author{
Laurent Dupont \\ Université de Lorraine \\ ERPI \\ F-54000 Nancy, France \\ 1.dupont@univ-lorraine.fr
}

\author{
Mauricio Camargo \\ Université de Lorraine \\ ERPI \\ F-54000 Nancy, France \\ mauricio.camargo@univ-lorraine.fr
}

\author{
Ferney Osorio \\ Universidad Nacional de Colombia \\ Departamento de Ingeniería de Sistemas e Industrial \\ Bogota, Colombia \\ fosoriob@unal.edu.co
}

\begin{abstract}
The creation of innovation laboratories within universities arises from the need to consolidate pedagogical and research aspects. These innovation laboratories are becoming key spaces for the development of innovation competences. In this article, we describe the experiences of developing a pilot project on distributed recycling approach. The results showed how the development of this project can play a role in strategy development at the innovation laboratory level. These insights are pertinent for the managers of these spaces to identify competencies to develop in the middle/long term. The development of methodological tools to connect the operational, tactical and strategic levels and competences for these spaces are important future paths of development
\end{abstract}

Index Terms-innovation labs; strategic intent; distributed recycling; Green Fablab

\section{INTRODUCTION}

The development of innovation laboratories (hereafter innovation labs) within different contexts including business, public and educational is having a growing interest in recent years in the academic and industrial landscape [1], [2]. Some reasons include that these spaces can favor the development of competences of innovation and collective creativity [3] and new working practices that rely on collaboration, co-design, co-production, co-creation approaches [4]. From the industrial point of view, these spaces are perceived as catalyzers with the purpose of improving the firm's capabilities to develop new products aligning the strategic intent of the company or organization and reducing the time-to-market [5], [6]. From the territorial point of view, the creation of these spaces within the context of public administrations is opening up new forms of 'deinstitutionalization' of policy advice systems, making room for co-production and citizen participation in the process of creating public policies [7]. In the citizen arena, the notions of "personal fabrication", Do-It-Yourself practices or "making" is often social and collaborative approach, entailing sharing and modifying online designs, cooperation on projects and/or shared use of tools in shared spaces [8]. As a consequence, there is a proliferation of diverse types of spaces with spatial practices that provide material and social environments for these initiatives such as hackerspaces, makerspaces, fablabs, open workshops, living labs, co-working spaces [2].

The influence of the physical space in the processes of creativity has been one of the preponderant topics from the managerial point of view [9], [10], creating opportunities to (1) engage with people, ideas and technologies; (2) experience participatory culture; and (3) acquire the literacy and skills needed to the current industrial context [2]. Moreover, different conceptual frameworks have been developed to understand the key requirements that need to be considered in order to study the actual capabilities of innovation labs. Also, to what degree of expertise their practices and processes could be determined by proposing a maturity grid-based assessment tool [2]. The structure of these innovation labs depends upon the strategic intention and the context they are participating [1].

In this paper, we focus on innovation labs inside higher education institutions because these spaces can play an increasingly important role in collaborative learning [11]. For universities, this type of space is a key driver to support teaching and research developing new strategies to the current education standards [12]. Moreover, this research enables us to forge ties with the industrial sector thanks to the cocreation of complex projects among professors and students from different disciplines enabling a closer relationship with the industry creating new research agendas. Projects initiated in innovation labs -especially experimentation-oriented onesoften target societal challenges, such as sustainability, upcycling, or civil participation in knowledge dynamics and technology [13]. Therefore, the innovation labs contribute to social value generation by enabling "experimentation for the sake of experimentation" [14] and for making something meaningful to be used, thus embracing the cultural value of making [15].

However, even if there have been advancements in the 
strategic design and configuration of innovation spaces across a variety of academic disciplines, such as management and organizational studies, sociology, or entrepreneurial studies, there remains a need for establishing practical elements for piloting this type of structural projects. Further questions appear in the tactic and operational levels: How to pilot a project within an innovation lab in a university context? What could be the guidelines for the development of projects that are evolutive? More research is needed to show the co-evolutionary aspects of the innovations spaces and the projects developed within it. This brings lab managers and researchers to the forefront because they transfer information, try to create a place-based community, and promote linkages between users in the space, and yet also do so between users and organizations outside the space.

In this paper we present the experience of the development of the Green Fablab project at the Lorraine Fab Living Lab ${ }^{\circledR}$ [16]. The main goal of this paper is thus to provide insights from empirical work on how a pedagogical recycling project is developed within an innovation lab in order to observe the evolution of the strategic intent of both the project and the innovation lab. In order to do this, a conceptual framework originally conceived for providing guidance in the design and management of innovation labs [2], [17], has been used to analyze the evolutionary stages of a project inside an innovation lab. Then, a cross-case analysis is structured in order to reflect on the 7 groups of students who have participated in the Green Fablab project in a period of two years and a half. The results allow us to observe that the development of a project can influence the strategy of an innovation lab, and also, this approach could allow innovation lab managers to identify competencies to develop in the middle/long term.

The remainder of this document is structured as follows. First, an overview on innovation labs inside higher education and sustainability dimension is explored. Then, the methodological approach is explained including our research design. Afterwards, results and analysis are discussed leading finally, to our conclusion.

\section{EXISTING THEORIES AND PREVIOUS WORK}

\section{A. Innovation labs in the higher education context}

The creation of innovation labs within universities arises from the need to consolidate pedagogical and research aspects. Miranda et al. [12] described how innovation spaces are facilitators of the vision of Education 4.0 having as reference the open innovation paradigm. They presented the case of the 'Open Innovation Lab' developed inside the Tecnológico de Monterrey, México, where two cases with industries were described having three main conceptual elements (1) learning methods, (2) design methodologies and (3) prototyping platform. In the same line, Delgado et al. [11] highlighted important factors from several dimensions (physical, technological, emotional, social and cognitive) in order to encourage collaborative learning. Based on this, they present the strategic action plan they considered to set-up the innovation lab within the University of Santiago de Chile. Chint et al. [18] explored the conjunction of living lab approaches, the internet of things dimension in order to describe a pervasive-interactiveprogramming $(\mathrm{PiP})$ paradigm within the framework of a strategy to improve pre-university options in the UK. A case study was presented to see how the staff of various backgrounds (including non-programmers) were able to quickly master the skills and understand the concepts involved in mastering computer science. Barth et al. [19] presented the case of a fablab within the University of Halmstad where he concludes that the teaching carried out must be flexible and open to pedagogical challenges when students and groups of students explore new ways of solving a problem, which is not always related to standardized methods and procedures.

\section{B. Sustainability dimension in innovation spaces}

The democratization of innovation labs, including digital manufacturing capacity, has led to the concept of consumers/prosumers. The innovation labs support the do-ityourself practices, implying that the final user is an integral part of the production of his own products [20], [21].

Environmental implications of the personal fabrication considering the proliferation of peer-to-peer practices have been highlighted by [22], [23]. They identified opportunities to promote environmental sustainability through four main drivers namely (1) Product longevity, (2) Co-design, (3) Local production and (4) Technology affordance.

Product longevity relies on the hypothesis that technologies such as additive manufacturing enable personalization advantages for tackling obsolescence. Sustainability paradigms as the circular economy approach support this trend [24] in which the design product needs to consider principes of waste minimisation, retention of value for larger cycles, and striving for closed-loop approaches within the boundaries of environmental protection and socioeconomic benefits. Codesign strategy intends not only to inform the consumer about -e.g. environmental impacts- in production and/or use, but also to allow sustainability constraints. A strategy of cleaner prosumption reconsiders not only how something is produced, but what is produced (or prosumed) and why. From a local production perspective, the $\mathrm{R}$ practices (reduce, recycling, recover) are noteworthy strategies to foster inside these open spaces. Finally, the technology affordance makes emphasis on the research and development of technologies to allow their users to operate with more environmentally responsible practices (e.g. use recycled materials by default).

This literature confirm that the innovation labs and sustainability practices have a common space. However, there remains to understand how a project dynamic can give insights to the strategy of the innovation lab. Thus, in the next section the case study is presented where the aim is to develop sustainability dimensions through the plastic recycling process inside an innovation lab.

\section{RESEARCH DESIGN}

This work is part of ongoing research on the creation and management of innovation labs to understand the role and 
impact they can have within an ecosystem (industrial, public, educational) [2]. Through a conceptual framework (Figure 1), the authors analyze the process of creation of an innovation lab as a 'milieu' that embodies the innovation intent of an organization or group of organizations.

They also consider the process by which such space is actually used, and the innovation outcomes generated. This approach has already been tested to assess the organizational capabilities of an innovation lab but and to understand its evolutive stages from a managerial point of view [2], [17]. Given that the purpose of this paper lies in reflecting on the evolution of a pedagogical project within an innovation lab, we believe the latter is a valuable approach in this case. However, since this framework has so far only been applied at the lab management level, some considerations should be taken into account to focus on the project level.

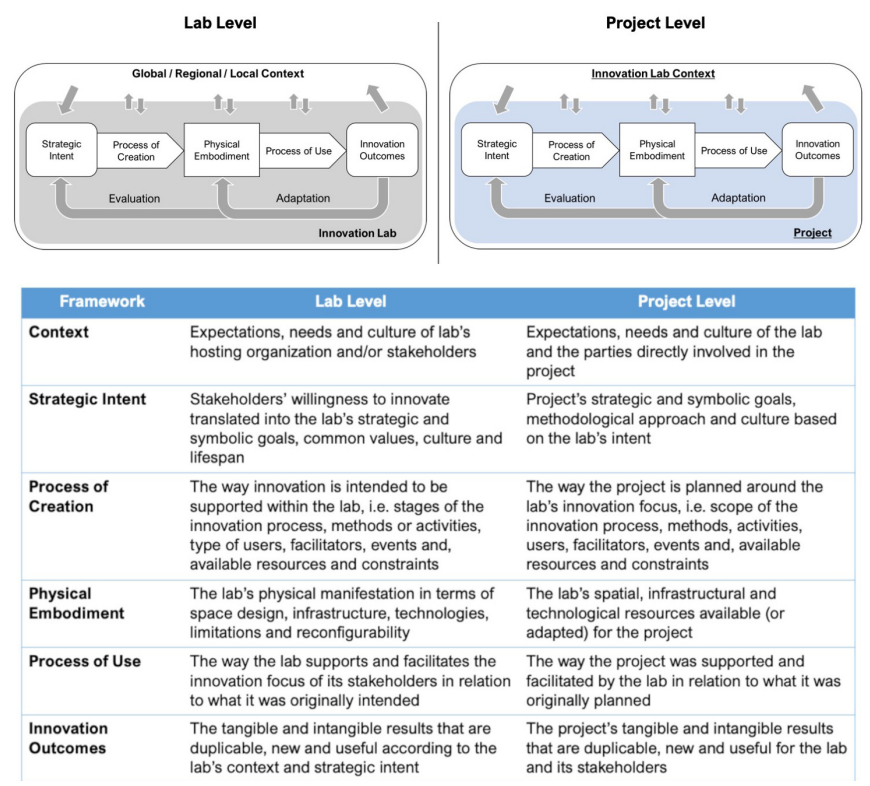

Fig. 1: Theoretical framework of the analysis for the case studies based on [2]

This study is mainly focused on the experience of the seven groups of students that have been involved in the Green Fablab project. The project's official documents, the students' final reports, posters and prototypes, and participant observations from two of the authors as the students' supervisors are the main sources of information. Then, through a cross-case analysis it is intended to examine how the Green Fablab project has been developed and to what extent this initiative has contributed to the creation of new capabilities for the Lorraine Fab Living $\mathrm{Lab}^{\circledR}$, but also to the strengthening of inter-institutional collaboration between the two engineering schools (CESI and ENSGSI) that are involved. . Figure 2 summarizes our research design along with the main sources of data considered in the analysis. In the next section, the results of the cross-case studies are presented.

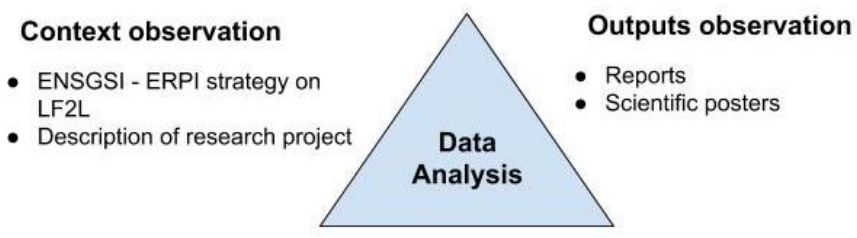

Participant observation

- Research advisors of the project

- Technical manager of the LF2L

Fig. 2: Research design and main sources of data.

\section{RESULTS}

This section presents the analysis of the observed case studies through the five points of interest of the conceptual framework. A total of seven cases were analyzed, each one corresponds to a five-week internship with a student or two at the same time. Table I provides a summary of the main elements retrieved from the data of the project development.

\section{A. Context}

The Lorraine Fab Living Lab $^{\circledR}\left(\mathrm{LF} \mathrm{L}^{\circledR}\right)$ is a research platform developed by an engineering school ENSGSI school and the ERPI laboratory of the Université de Lorraine since 2014 [16]. It is configured with a living lab space to offer users a set of dedicated tools for the co-creation process (creativity, brain/bodystorming), enabling a spatial reconfiguration, participant observation, tools for visualization, and ICT to support distributed group work. Moreover, a materialization space is available to the development of projects that take the advantage of digital manufacturing capabilities.

The methodological approach 2D-3D-4D consists of in a series of stages from idea generation (2D), concept creation (3D) towards an evaluation of usage scenarios (4D) taking as a baseline the user-centered approach [25].

The Green Fablab is one of the projects inside this innovation lab that is a transversal thematic to the engineering students of the ENSGSI, and researches of the ERPI laboratory. Figure 3 presents the initial experimental setup. The longterm goal is to develop closed-loop and local plastic recycling scientific demonstrator process, using the open-source 3D printing and the innovation labs as facilitators, understanding the socio-technical invariants and sustainability dimensions. Moreover, the study of sustainable solutions developed at the LF2 $\mathrm{L}^{\circledR}$ can be part of the consolidation and reinforcement of the links with the local ecosystem in which this space is located, taking into account the strategic direction at city level in terms of ecological transition [26]. The previous studies within this project focused on the technical validation of the printing [27] and plastic recycling [28] and logistical consideration [29], [30] processes under scientific laboratory conditions. However, from a research perspective, the interest is to study how this process could be democratized based on the user/community-innovation paradigms [31], [32], enablign the notion of distributed recycling. From the operational level, the main intention is to develop a low-cost experimental setup 
TABLE I: Summarized results of framework application for the Green Fablab project

\begin{tabular}{|c|c|c|c|c|c|c|c|}
\hline & Case 1 & Case 2 & Case 3 & Case 4 & Case 5 & Case 6 & Case 7 \\
\hline Timing & May-June 2017 & Sept-Oct 2017 & Feb-Mar 2018 & Oct-Nov 2018 & Jan-Feb 2019 & May-June 2019 & Dec-Jan 2019 \\
\hline \# of students & 2 & 2 & 1 & 2 & 2 & 1 & 1 \\
\hline Context & \multicolumn{4}{|c|}{ Filament extrusion of recycled polymer } & \multicolumn{2}{|c|}{ Mobile extrusion for local recycling } & Direct extrusion \\
\hline Strategic intent & $\begin{array}{lr}\text { Create } & \text { feedstock } \\
\text { for } 3 \mathrm{D} & \text { printers } \\
\text { from } & \text { virgin } \\
\text { material } & \\
\end{array}$ & $\begin{array}{l}\text { Create a feeding } \\
\text { prototype for ex- } \\
\text { trusion process }\end{array}$ & $\begin{array}{lr}\text { Connect } & \text { feeding } \\
\text { and } & \text { extruder } \\
\text { systems } & \text { for } \\
\text { recycled feedstock }\end{array}$ & $\begin{array}{l}\text { Documentation } \\
\text { and safety issues } \\
\text { of extrusion } \\
\text { process }\end{array}$ & $\begin{array}{l}\text { Mobility structure } \\
\text { for extrusion }\end{array}$ & $\begin{array}{l}\text { Improvement of } \\
\text { mobility structure }\end{array}$ & $\begin{array}{l}\text { 3D Printing via } \\
\text { fused granular } \\
\text { fabrication }\end{array}$ \\
\hline $\begin{array}{l}\text { Process of cre- } \\
\text { ation }\end{array}$ & $\begin{array}{l}\text { Experimental } \\
\text { setup }\end{array}$ & $\begin{array}{l}\text { Innovation steps } \\
(2 D-3 D-4 D)\end{array}$ & Experimental test & $\begin{array}{l}\text { User experience } \\
\text { Division of tasks }\end{array}$ & $\begin{array}{l}\text { Innovation steps } \\
(2 D-3 D-4 D)\end{array}$ & $\begin{array}{l}\text { Innovation steps } \\
(2 D-3 D-4 D)\end{array}$ & $\begin{array}{l}\text { Experimental } \\
\text { setup }\end{array}$ \\
\hline $\begin{array}{l}\text { Physical embod- } \\
\text { iment }\end{array}$ & $\begin{array}{l}\text { Semi open-source } \\
\text { (OS) extruder / fil- } \\
\text { ament collector }\end{array}$ & $\begin{array}{l}\text { Mechanical } \\
\text { / Electrical } \\
\text { prototyping }\end{array}$ & $\begin{array}{ll}\text { Feeding } & / \\
\text { Extrusion } \\
\text { collector setup }\end{array}$ & ICT equipment & $\begin{array}{l}\text { Wood prototyping } \\
\text { equipment }\end{array}$ & $\begin{array}{l}\text { Wood prototyping } \\
\text { equipment }\end{array}$ & $\begin{array}{l}\text { Open-source kit } \\
\text { extrusion / Semi } \\
\text { OS 3D printer }\end{array}$ \\
\hline Process of use & $\begin{array}{l}\text { Experimental plan } \\
\text { to test the ma- } \\
\text { chines / Problem } \\
\text { solving approach }\end{array}$ & $\begin{array}{l}\text { Innovation steps / } \\
\text { Division of tasks }\end{array}$ & $\begin{array}{l}\text { User experience } \\
\text { for improving } \\
\text { feeding } \quad \text { and } \\
\text { extrusion }\end{array}$ & $\begin{array}{l}\text { Documentation } \\
\text { using Open source } \\
\text { tools }\end{array}$ & $\begin{array}{l}\text { 2D design of mo- } \\
\text { bile structure }\end{array}$ & $\begin{array}{l}\text { 3D-4D of mobile } \\
\text { structure }\end{array}$ & $\begin{array}{l}\text { Experimental } \\
\text { setup with fused } \\
\text { granular kit }\end{array}$ \\
\hline Outcomes & $\begin{array}{l}\text { Identification of } \\
\text { technical issues to } \\
\text { resolve }\end{array}$ & $\begin{array}{l}\text { Creation of a } \\
\text { feeding system }\end{array}$ & $\begin{array}{l}\text { Modification } \\
\text { of project } \\
\text { management }\end{array}$ & $\begin{array}{l}\text { Knowledge man- } \\
\text { agement for the } \\
\text { prototype }\end{array}$ & $\begin{array}{l}\text { Technical } \\
\text { improvement }\end{array}$ & $\begin{array}{l}\text { Technical } \\
\text { improvement }\end{array}$ & $\begin{array}{l}\text { Scientific } \\
\text { and research } \\
\text { opportunity }\end{array}$ \\
\hline
\end{tabular}

for ENSGSI and CESI students, so that they themselves can co-design the recycling process.

A total of 11 students divided into 7 different groups from the CESI engineering school from Nancy participated in the project. The engineering cycle of CESI engineer school proposes an alternative education where the students are $50 \%$ of the time in presence-based courses and the other 50\%, they work in an industrial company. The background of the students was diverse given the fact that they worked for companies in different activity sectors (industry, energy, tertiary), size (SMEs or large international groups) and role (quality, maintenance, safety). The mission was 5 consecutive weeks and had to prepare systematically a scientific poster and present their results to the research platform team. The interest of CESI engineer school is to allow their students to get immersed in a scientific research project. These cases were spaced for a period of two and a half years. The trainees were in the second year of the engineering cycle and this mission is mandatory in their academic curriculum to obtain the final degree.

\section{B. Description of cases study}

We detail the cases 1 and 2 to understand the results of the table I in a vertical reading as an example.

Initially, the supervisors had a clear idea of the objective of the project, and thus, the strategic intent was to manufacture feedstock filament for open source 3D printers from virgin pellet materials in-situ. The aim was to identify the important factors to take into account to extrude thread with good quality. Moreover, the background literature of the project showed that this approach provides an economical and environmental benefit [33].

Therefore, the process of creation designed for this mission was to establish an initial planning for each week. The first week was the introduction to the project, the environment, and the project's challenges to overcome. The main output of this first week was to establish the factual objectives for the following 4 weeks. The intermediate weeks 2-3-4 correspond to the progress of the project, taking as milestones the identification of the methodology to work (week 2), and then implementation/prototyping of intermediate objects of design (week 3-4). The last week was focused on the realization of a technical report and a scientific poster ecplaining the development of the mission.

The physical embodiment for the missions included the use of a semi-open source extruder machine, a filament collector kit, and a representative 3D printer. Gauging tools and protection tools were also planned.

Concerning the process of use for case 1 , one of the first elements that happened was to consider the level of student's competence that there were no previous to the plastic industry. Initially, some scientific articles were given to the students to understand the project. But additionally, the tutors observed that it was necessary to do experimental work in order to understand the potential problems of working in a filament extrusion process. Thus, the importance of the first week is to try to replicate what the students could find about the machine and extrusion from different sources, (e.g. internet, videos, blogs). The supervisors realized that this learning-bydoing approach was more adapted to the nature of this project, acknowledging that the students already work in an industrial context.

Moreover, the equipment used was a prototype under development, which led to permanent technical problems (and machine breakdowns). These elements were not considered at the beginning of the project.

Based on these firsts insights, there were outputs from the tangible and intangible view. From the tangible perspective, a first manual of the use of the extrusion machine was obtained for case 1 and a first plan of experiences made with the 
objective of seeing factors that could influence the quality of the virgin filament diameter. Likewise, when using recycled material, the tutors realized that it was not enough for the initial experimental setup. From intangible outputs, the supervisors declared that students found the mission interesting because of the exploratory nature of the subject, allowing them to get out of the industry in which they routinely work. Although it is difficult to quantify these, the perceptions were considered important to valorize through the website of the project.

Concerning case 2, due to the unforeseen events of the machine (machine under repair), and seeing the results of the first group, the strategic intent was the creation of a feeding system for the extrusion process. This decision allowed the students and the project to move forward even if the extruder was not available. The planning was also given by the tutors from the beginning with the process of creation about innovation steps 2D-3D-4D. The students had access to all the equipment and machines available, apart from external reservations during the internship.

In the process of use of case 2, the students concluded that it was necessary to work on two distinct but complementary fields after the introduction week: electrical and mechanical. This was the first time that the students proposed to reorganize the management of the project. The supervisors did not identify that before at the beginning of the mission. After a presentation to the supervisors and their validation, the students divided up the tasks and worked each on one field, considering the needs of the other throughout the project. With this change, the students have achieved the initial objective and realized a functional pellet feeding system. They have developed the first prototype of a mechanical system to avoid pellet jamming in the extruder and to connect a feeding system to the prototype. A technical document was done describing the ideation, materialization and the maintenance of the overall proposed system, highlighting potential issues to be resolved.

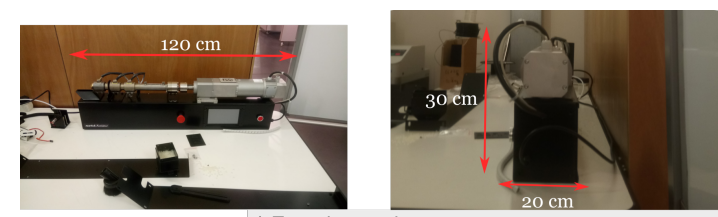

c) Extruder semi-open source
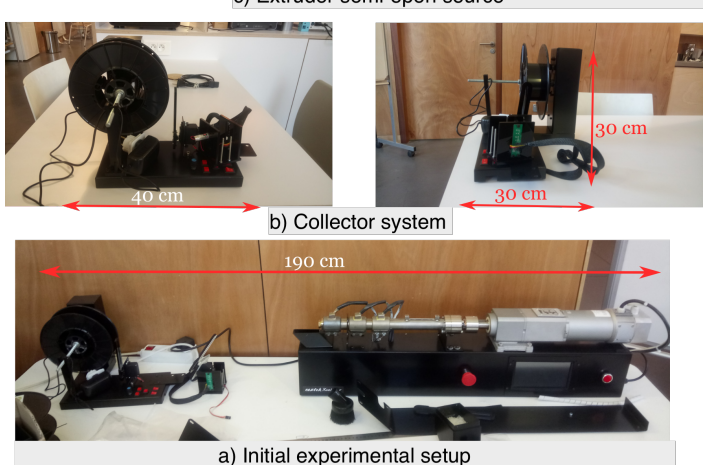

Fig. 3: Initial experimental setup for the Green Fablab project.
The outcomes were essentially a first technical insight about the feeding systems including a prototype. Another meaningful insight concerned the management of the project and its modification after the proposal of the students. Beyond the direct modification of the management of their own project, some of their proposals have been retained for the next group of trainees. In this case, the mission goal has been influenced by external events (maintenance of the extruder), as well as by internal reorganizations (change in project management) and that outcomes, beyond technical or scientific point of view, influence the management of future cases.

In the following section, we will concentrate on each aspect of the five dimensions, to see the changes in the evolution of the project.

\section{Strategic Intent}

The strategic intent was directly related to the project context and the experimental output including the issues found. The development of this type of internship (5 weeks / plurality background), combined with the strategic intent of the $\mathrm{LF}_{2} \mathrm{~L}^{\circledR}$ to highlight the durable dimension of 3D printing forced the supervisors to give precise objectives and to follow the trainees' work precisely. Three types of strategy can be distinguished. The objectives cases 1-4 were clearly identified objectives from the start of the internships with the purpose of creating filament feedstock inside of the innovation lab. Case 1-2 were explained in detail before, concerning cases 3 , the main idea was to connect the development of cases 1-2 in one functional prototype. Nevertheless, case 4 presented a slight difference because the goal was co-created with the students based on the student's background. The goal for this mission was focused on the documentation and initial specification of the safety issues of having an extrusion process inside the innovation lab. In these four cases, the implicit fact was that the prototype would be fixed inside the LF $2 \mathrm{~L}^{\circledR}$ facilities. A new insight was considered for cases 5-6 in order to develop a mobile extrusion prototype. From a strategic dimension of LF2 $\mathrm{L}^{\circledR}$, the aspect of the mobility was important in terms of the possibility of presenting the project outside the facilities, and also, the internal organization to optimise the available physical space.

Finally, a third change of strategic intent was identified. The research of plastic recycling via additive manufacturing presented an important input in terms of technology development. The initial implicit was to create recycled filament as a valuable asset. However, recent research studies proved the technical viability of using recycled particles using the technology known as Fused Particle Fabrication / Fused Granular Fabrication [34], [35]. This insight made rethinking the whole recycling process because it was not necessary to create filament but the recycled printed object as the valuable asset. In consequence, the strategic intent of Case 7 was precisely to explore the dimension of the direct extrusion printing process from the recycled pellets.

In summary, it is observed that cases 1 to 3 were particularly creation/explorative missions to put in place a first initial 
prototype. Cases 4 to 6 were focused on the integration and the optimization of the mobile structure. And case 7 , being a conceptual upheaval, was an explorative new approach to fabricate recycled objects directly.

\section{Process of creation}

The process of creation represents steps planned before the students start. The segmentation for milestones each week was conserved throughout the whole cases. Based on the learnings of case 1, supervisors adopted that the first week needs to be experimental with 'DIY' practices, allowing the students to test by themselves the potential issues that the prototype could have. Also, one of the outputs from case 4 was the establishment of a wiki as a knowledge management model to capitalize on the advancements of precedent students. This practice was perceived useful by the supervisors for the first week, giving space to the student to understand with their own representation the global project. An interesting element to highlight is the division of tasks based on the students' skills. One of the first elements of the discussion of the introductory week related to the student's experience background to see what competence could fit the project development.

The creation of the poster at the end, it was valuable in order to recapitulate the mission. . The approach 2D-3D-4D was the first guide to design the mission.

These steps were necessary for the students to imagine new ideas and solutions to meet the needs of the project.

\section{E. Physical Embodiment}

The technical context was the same for all the cases, having access to the physical conditions presented at the $\mathrm{LF}_{2} \mathrm{~L}^{\circledR}$. Each student had his own desk and computer and had access to all the equipment available including $3 \mathrm{D}$ printers, laser-cut, numeric tools, electronic tools. Here, the interaction of the students with the technical manager was a key element with the purpose that they become autonomous in the use of the machines at the first week. Particularly, it was concluded that the competences CAD, 3D printing, and electronic (Arduino) were important for cases 1-3. For cases 4-5, implying a higher scale for prototyping, the physical space of LF2 $\mathrm{L}^{\circledR}$ needed to adapt it to work with wood materials.

Concerning the prototypes, the students interacted with the extruder machine using the configurations developed on the previous works to obtain recycled filament. Nevertheless, it was observed by the supervisors that the interaction and documentation of the feeding prototype (case 2) was a critical factor for the cases 4-7, needing more maturation and development to have a more robust version. Finally, even if case 7 was a project corresponding to the new concept about direct extrusion, the digital manufacturing capabilities (CAD, lasercut, 3D printing) were useful to the (re)design and adapt the prototype.

\section{F. Process of Use}

The supervisors found that not in all cases the notion of 2D3D-4D was used in the same way and with the same intensity.
Case 1 and 7 had a dynamic setting up an experimental assembly within the platform. However, cases $2,3,5$ and 6 had a more pronounced inventive dynamic. Activities of cocreation and materialization such as creativity, formalization of ideas, design iteration loops were confirmed in these cases. The interaction of technical responsibility of the LF2 ${ }^{\circledR}$ with the students was a valuable resource in terms of insights for the students to imagine the prototype usability. Nevertheless, the activities in terms of user experience with general users (visitors and general public of the $\mathrm{LF}^{2} \mathrm{~L}^{\circledR}$ ) evaluation were difficult to implement given the timing and prototype's maturity.

Another fundamental point relies on the capacity for reparability. This competence is generally relegated to outside the domains of the laboratory at the university. However, it was noted that it is essential to be able to keep it in mind when making projects within these spaces.

\section{G. Innovation Outcomes}

The tangible results of these cases consisted on the development of experimental prototypes. This is particularly important because in a scientific laboratory condition, the cost of experimental setup could be high (about $€ 100 \mathrm{k}$ ). Here the cost of the prototypes was reduced about 5 times. Another tangible output is related to the "identification of issues to resolve" in each case. The supervisors were able to evaluate if these elements could be considered in a research or technical domain. For instance, the development of a mobile structure (cases 5,6) fall into technical development. However, case 7 opened-up and revealed a gap in the scientific literature that was explored in a research study [36].

From the intangible output, the development of these cases was among the first steps of collaboration including the technical, doctoral and post-doctoral students of ENSGSI, CESI and ERPI laboratory. These was valuable interaction giving the different background of the students. The students brought their new vision and proposed, in some cases, their own system of internal organization. Likewise, the profile of the recruited trainees evolved as the project did.

By working with this type of apprentice profile and observing their working method given the industrial background, the supervisors adapted the recruitment to finally have apprentices with different technical, scientific and transversal skills. Figure 4 gives an overview of the evolution of the outcomes.

\section{DisCUSSION AND LIMITS OF THE RESUlTS}

This article described the experiences of developing a pilot project on distributed recycling approach developed at an innovation lab inside a higher education institution. This is an ongoing research with the main aim to understand how the global strategies of an innovation laboratory match with the development of internal projects.

The hypothesis from this methodological approach is to be able to identify practices, competences and routines that in the long-term can be aligned and create eventually synergy among 


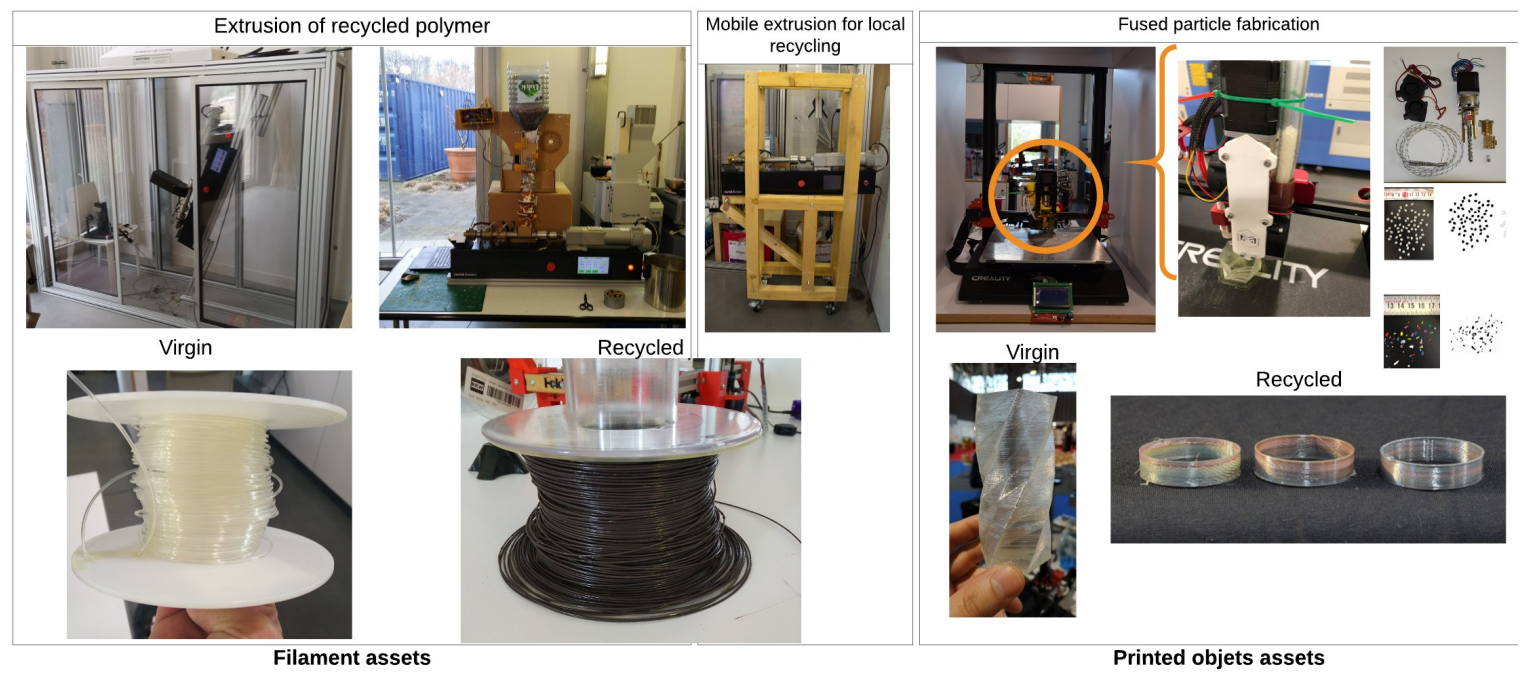

Fig. 4: Results of the evolution of the project intent

the multiplicity of projects/activities that can be developed inside these spaces.

One of the first elements to highlight is that the collaborative dynamics within this space enabled the strategic objective of the project to evolve. Table II presents the evolution of the strategic intent in a lab level and project level dimensions.

TABLE II: Evolution of the strategic intention

\begin{tabular}{l|l}
\hline \multirow{2}{*}{ Innovation lab } & Project \\
\hline \multirow{3}{*}{$\begin{array}{l}\text { Create prototypes from } \\
\text { recycled wastes }\end{array}$} & $\begin{array}{l}\text { To fabricate feedstock material for the 3D } \\
\text { printers at the LF2L }{ }^{\circledR}\end{array}$ \\
\cline { 2 - 2 } & $\begin{array}{l}\text { To fabricate feedstock material using the } \\
\text { internal plastic wastes from the 3D printers to } \\
\text { be reused inside }\end{array}$ \\
\cline { 2 - 2 } & $\begin{array}{l}\text { To develop a 3D printer machine that use } \\
\text { directly wastes without the need to } \\
\text { manufacture filament. }\end{array}$ \\
\hline $\begin{array}{l}\text { To have a pedagogical } \\
\text { demonstrator to } \\
\text { distributed recycling } \\
\text { approach }\end{array}$ & $\begin{array}{l}\text { To have a robust process to recycled potential } \\
\text { waste from a local radio (less than 2 km) of } \\
\text { the LF2 }{ }^{\circledR} \text { to be used as feedstock material } \\
\text { for 3D printers }\end{array}$ \\
\hline
\end{tabular}

From a project point of view, there has been a transition in the project strategy. The initial intent focused on developing the recycling competence using the waste of recycling 3D printers' scraps inside the $\mathrm{LF} 2 \mathrm{~L}^{\circledast}$ with the objective of creating raw materials (virgin, recycled) for the printers. The case studies 1-4 were aligned to this ambition, and the project proved the technical feasibility to fabricate these feedstock using the internal plastic wastes from the 3D printers.

Nonetheless, this initial view changed to an intent of creating a robust local recycling process, where not only the technical part of printing recycled objects is considered, but also elements of collection, sorting and pre-treatment in order to reuse these secondary materials. According to the supervisors, the dynamics of interaction between students, researchers and the general public were factors linked to this change in the strategy. It should be noted that the field of 3D printing today has a significant disruption in view of the opportunities that can unleash at different levels [37], and the scientific advancement of the literature also contributes to rethinking the intention of the project.

Therefore, connected to this evolution of the project's intent, part of the the LF2L $\mathrm{L}^{\oplus}$ strategy has also changed from the simple creation of recycled prototypes indoors for students' use to the objective of becoming a local demonstrator of distributed recycling. From these elements, innovation labs are considered to be embedded within spatio-temporal innovation processes that eventually could be a driver or initiator of innovation [4].

In the process of creation level, a point to highlight is the notion of open hardware development as an alternative of traditional plug-and-play technical devices in the context of scientific equipment. The integration of open hardware development within traditional education systems opens up possibilities in both pedagogical and research aspects [38]. The development of open hardware scientific equipment is getting attention thanks to the high profit/cost ratio, guaranteeing a technical performance equal or superior to traditionally manufactured equipment [39]. However, the exploratory results showed that cooperative work is difficult to put into practice given levels of competences in terms of mechanical design, even if the technical platform allows the creation of certain prototypes by students. For the project, the creation of open hardware is seen as a strategic intermediate goal to create low-cost, reparable and reproducible technical solutions.

In the dimension of physical embodiment at the innovation lab level, the identification of the competencies and resources that are required to establish a technological ecosystem (tools and means of production) based on the open hardware paradigm is an input from the project.

In the process of use from a pedagogical aspect, one lesson learned expressed by the tutors concerns the definition of the type of prototype before the internship starts. From 
the prototyping theory, the creation of prototypes ranging from low fidelity (simple physical models) to high fidelity (fully functioning devices or systems) are used throughout the design process to communicate ideas, test assumptions, receive insights and interact with users [40]. However, it is noticed that novice designers hold imprecise and incomplete perceptions about the purpose and value of prototypes and prototyping activities within the design process. Certain ideas were not developed because it was not clear the purpose of the prototype (model to Link, to test, to communicate, to decide, or to interact [40]).

In terms of outcomes, one learning experience confirmed by the supervisors related to the innovation space can be regarded as liminal spaces that facilitate individual and collective development and comprise processes of transformation of the space itself [4]. The decision to create a mobile recycling process is related in part to the fact that space itself needs to evolve, thus the modularity aspect was added in the project development. Likewise, results from this experience also evidence the functional role of innovation labs on bringing technologies accessible for experimentation which allows project teams to focus in the collaborative innovation process [8].

Another noteworthy learning lies on the variety of outcomes throughout a project that could serve as an input for the laboratory level. Looking at our cross-case analysis it was possible to observe how an innovation lab in pedagogical environment can indeed be a driver not only to alternative ways of teaching and learning but also to diverse results (e.g. technical manuals, prototypes, dissemination material, research opportunities) which can feed the laboratory strategy and operation. This should be of special attention to lab teams since innovation lab outcomes lie on a variety of tangible and intangible results which should be considered altogether for tackling the sense of 'unrealized intention' that often comes when assessing innovation labs performance [2], [5]

Moreover, projects hosted in an innovation lab serve as experimentation arenas bringing together multiple stakeholders and sparkling the collaboration process amongst them. The innovation lab in this case has reunited not only students from multiple backgrounds and skills but also has been an interinstitutional meeting point for two engineering schools and one research institute. Collaborative dynamics under these levels of multiplicity of intents, expectations and ways of work demand for high levels of trust, flexibility and adaptation which directly impact how projects and activities in innovation labs are carried out [19].

Overall, the present work provides a glimpse on how the chosen framework could work as a methodological approach to uncover the co-evolutionary relations between an innovation lab and the projects undertaken within it. In this sense, its comprehensive approach that addresses strategic, tactical and operational aspects enables the identification of detailed practices and routines. Open-hardware, prototyping, modularity and interinstitutional collaboration are some of the competences that emerge from this case. Further, the possibility to analyze the project-laboratory relation invites to explore how project outcomes in addition to generate new competences to the innovation lab, also become a source of learning for its stakeholders, as originally argued by [6].

In terms of the limits, this article relies mostly on the perspective of the tutors and the technical staff who were involved in the process. Despite the value of the results presented here according to the purpose of this article, the students' perspective remains as a key aspect to consider in the future. In fact, their perspectives (beginning and end) of the internship is seen as major source information to be collected in order to analyze the evolution in terms of competences and interactions. For these, opportunities to do research using qualitative methodologies (interviews, focus group) is a future path to explore.

\section{Conclusions}

The innovation lab inside universities is one opportunity not only to develop pedagogical projects but also, to connect with the scientific research. These spaces are thought of as a means of supporting innovation projects. Therefore, the objective of this article is to describe the development of an innovative project on the recycling dimension for $3 \mathrm{D}$ printing called Green Fablab using a conceptual framework originally conceived for providing guidance in the design and management of innovation labs. The aim is to see how the development of an innovation project developed in these spaces is able to give inputs to the global strategy of the innovation lab. One main conclusion of the case studies is that the strategic intent of both the laboratory and the project evolves as a project develops, and therefore needs to be rethought from time to time. It is necessary to develop specific management tools for an innovation space, in order to create a synergy between the projects that can be developed inside, and the innovation capabilities in the short and medium term. Innovation labs are indeed complementary elements to existing knowledgegenerating organizations Therefore, future research must be done in terms of how the innovation process is fostered through the identification of practices and competencies identified within these spaces. Likewise, to determine the factors that encourage collaboration, so that the development of projects is further improved.

\section{REFERENCES}

[1] D. Uzunidis, L. Morel, L. Dupont, and M.-R. Boudarel, "Innovation Spaces: New Places for Collective Intelligence?" Collective Innovation Processes, pp. 87-107, 2018, doi: 10.1002/9781119557883.ch5.

[2] F. Osorio, L. Dupont, M. Camargo, P. Palominos, J. I. Peña, and M. Alfaro, "Design and management of innovation laboratories: Toward a performance assessment tool," Creativity and Innovation Management, Jan. 2019, doi: 10.1111/caim.12301.

[3] M. Caccamo, "Leveraging innovation spaces to foster collaborative innovation," Creativity and Innovation Management, no. November 2019, pp. 1-14, 2020, doi: 10.1111/caim.12357. 
[4] S. Schmidt, "In the making: Open Creative Labs as an emerging topic in economic geography?" Geography Compass, no. June, pp. 1-16, 2019, doi: 10.1111/gec3.12463.

[5] J. Moultrie, M. Nilsson, M. Dissel, U. E. Haner, S. Janssen, and R. Van der Lugt, "Innovation Spaces: Towards a Framework for Understanding the Role of the Physical Environment in Innovation," Creativity and Innovation Management, vol. 16, no. 1, pp. 53-65, 2007, doi: 10.1111/j.14678691.2007.00419.x.

[6] M. Lewis and J. Moultrie, "The Organizational Innovation Laboratory," Creativity and Innovation Management, vol. 14, no. 1, pp. 73-83, 2005, doi: 10.1111/j.14678691.2005.00327.x.

[7] M. McGann, T. Wells, and E. Blomkamp, "Innovation labs and co-production in public problem solving," Public Management Review, vol. 0, no. 0, pp. 1-20, 2019, doi: 10.1080/14719037.2019.1699946.

[8] S. Fox, "Paradigm shift: do-it-yourself (DIY) invention and production of physical goods for use or sale," Journal of Manufacturing Technology Management, vol. 24, no. 2, pp. 218-234, Feb. 2013, doi: 10.1108/17410381311292313.

[9] L. Gryszkiewicz, I. Lykourentzou, and T. Toivonen, "Innovation labs: leveraging openness for radical innovation?" Journal of Innovation Management, vol. 4, no. 4, pp. 68-97, 2017, doi: 10.24840/2183-0606_004.004_0006.

[10] T. Kristensen, "The Physical Context of Creativity," Creativity and Innovation Management, vol. 13, no. 2, pp. 89-96, 2004, doi: 10.1111/j.0963-1690.2004.00297.x.

[11] L. Delgado, D. Galvez, A. Hassan, P. Palominos, and L. Morel, "Innovation Spaces in Universities: Support for Collaborative Learning," Journal of Innovation Economics Management, 2020, doi: 10.3917/jie.031.0123.

[12] J. Miranda, C. S. Lopez, S. Navarro, M. R. Bustamante, J. M. Molina, and A. Molina, "Open Innovation Laboratories as Enabling Resources to Reach the Vision of Education 4.0," Proceedings - 2019 IEEE International Conference on Engineering, Technology and Innovation, ICE/ITMC 2019, 2019, doi: 10.1109/ICE.2019.8792595.

[13] E. Unterfrauner and C. Voigt, "Makers' ambitions to do socially valuable things," The Design Journal, vol. 20, no. sup1, pp. S3317-S3325, 2017, doi: 10.1080/14606925.2017.1352835.

[14] K. Fleischmann, S. Hielscher, and T. Merritt, "Making things in Fab Labs: a case study on sustainability and cocreation," Digital Creativity, vol. 27, no. 2, pp. 113-131, 2016, doi: 10.1080/14626268.2015.1135809.

[15] A. D. Roma, V. Minenna, and A. Scarcelli, "innovation Fab Labs . New hubs for socialization and innovation," The Design Journal, vol. 6925, pp. S3152-S3161, 2017, doi: 10.1080/14606925.2017.1352821.

[16] L. Dupont, L. Morel, and P. Lhoste, "Le Lorraine Fab Living Lab : la 4ème dimension de l'innovation," in Journées Hubert Curien, 2015.

[17] F. Osorio, L. Dupont, M. Camargo, C. Sandoval, and J. I. Peña, "Shaping a Public Innovation Laboratory in Bogota: Learning through Time, Space and Stakeholders," Journal of
Innovation Economics \& Management, vol. 31, no. 1, pp. 69100, 2020, doi: 10.3917/jie.pr1.0066.

[18] J. Chin and V. Callaghan, "Educational living labs: A novel internet-of-things based approach to teaching and research," Proceedings - 9th International Conference on Intelligent Environments, IE 2013, no. June, pp. 92-99, 2013, doi: 10.1109/IE.2013.48.

[19] H. Barth, "Fabrication Laboratory as the learning environment for higher education," IMCIC 2019 - 10th International Multi-Conference on Complexity, Informatics and Cybernetics, Proceedings, vol. 2, no. Imcic, pp. 194-196, 2019.

[20] R. Jiang, R. Kleer, and F. T. Piller, "Predicting the future of additive manufacturing: A Delphi study on economic and societal implications of 3D printing for 2030," Technological Forecasting and Social Change, vol. 117, pp. 84-97, Apr. 2017, doi: 10.1016/j.techfore.2017.01.006.

[21] T. Birtchnell and J. Urry, "3D, SF and the future," Futures, vol. 50, pp. 25-34, Jun. 2013, doi: 10.1016/j.futures.2013.03.005.

[22] C. Kohtala and S. Hyysalo, "Anticipated environmental sustainability of personal fabrication," Journal of Cleaner Production, vol. 99, pp. 333-344, Jul. 2015, doi: 10.1016/j.jclepro.2015.02.093.

[23] C. Kohtala, "Addressing sustainability in research on distributed production: an integrated literature review," Journal of Cleaner Production, vol. 106, pp. 654-668, Nov. 2015, doi: 10.1016/j.jclepro.2014.09.039.

[24] F. A. Cruz Sanchez, H. Boudaoud, M. Camargo, and J. M. Pearce, "Plastic recycling in additive manufacturing: A systematic literature review and opportunities for the circular economy," J. Clean. Prod., vol. 264, p. 121602, Aug. 2020, doi: 10.1016/j.jclepro.2020.121602.

[25] L. Dupont, L. Morel, and M. Pallot, "Exploring the Appropriateness of Different Immersive Environments in the Context of an Innovation Process for Smart Cities,' in 22nd ICE/IEEE International Technology Management Conference, 2016.

[26] "Osons ! nancy en transition écologique." https:// participez.nancy.fr/processes/osonsnancy.

[27] F. A. Cruz Sanchez, H. Boudaoud, L. Muller, and M. Camargo, "Towards a standard experimental protocol for open source additive manufacturing," Virtual and Physical Prototyping, vol. 9, no. 3, pp. 151-167, Jul. 2014, doi: 10.1080/17452759.2014.919553.

[28] F. A. Cruz Sanchez, H. Boudaoud, S. Hoppe, and M. Camargo, "Polymer recycling in an open-source additive manufacturing context: Mechanical issues," Additive Manufacturing, vol. 17, pp. 87-105, Oct. 2017, doi: 10.1016/j.addma.2017.05.013.

[29] P. Santander, F. A. Cruz Sanchez, H. Boudaoud, and M. Camargo, "Closed loop supply chain network for local and distributed plastic recycling for 3D printing: a MILP-based optimization approach," Resources, Conservation and Recycling, vol. 154, p. 104531, Mar. 2020, doi: 10.1016/j.resconrec.2019.104531. 
[30] S. Pavlo, C. Fabio, B. Hakim, and C. Mauricio, "3D-Printing Based Distributed Plastic Recycling: A Conceptual Model for Closed-Loop Supply Chain Design," in 2018 ieee international conference on engineering, technology and innovation (ice/itmc), 2018, pp. 1-8, doi: 10.1109/ICE.2018.8436296.

[31] E. Von Hippel, "Democratizing innovation.pdf." pp. 63-76, 2005, doi: 10.1111/j.1440-1754.2008.01424.x.

[32] C. Hienerth, E. von Hippel, and M. Berg Jensen, "User community vs. producer innovation development efficiency: A first empirical study," Research Policy, vol. 43, no. 1, pp. 190201, Feb. 2014, doi: 10.1016/j.respol.2013.07.010.

[33] C. Baechler, M. DeVuono, and J. M. Pearce, "Distributed recycling of waste polymer into RepRap feedstock," Rapid Prototyping Journal, vol. 19, no. 2, pp. 118-125, Mar. 2013, doi: 10.1108/13552541311302978.

[34] M. J. Reich, A. L. Woern, N. G. Tanikella, and J. M. Pearce, "Mechanical Properties and Applications of Recycled Polycarbonate Particle Material Extrusion-Based Additive Manufacturing," Materials, vol. 12, no. 10, p. 1642, May 2019, doi: 10.3390/ma12101642.

[35] A. Woern, D. Byard, R. Oakley, M. Fiedler, S. Snabes, and J. Pearce, "Fused Particle Fabrication 3-D Printing: Recycled Materials' Optimization and Mechanical Properties," Materials, vol. 11, no. 8, p. 1413, Aug. 2018, doi: 10.3390/ma11081413.

[36] A. Alexandre, F. A. Cruz Sanchez, H. Boudaoud, M. Camargo, and J. M. Pearce, "Mechanical Properties of Direct Waste Printing of Polylactic Acid with Universal Pellets Extruder: Comparison to Fused Filament Fabrication on OpenSource Desktop Three-Dimensional Printers," 3D Print. Addit. Manuf., vol. 111, no. 2, p. 3dp.2019.0195, Apr. 2020, doi: 10.1089/3dp.2019.0195.

[37] M. Despeisse et al., "Unlocking value for a circular economy through 3D printing: A research agenda," Technological Forecasting and Social Change, vol. 115, pp. 75-84, Feb. 2017, doi: 10.1016/j.techfore.2016.09.021.

[38] J. L. Irwin, J. M. Pearce, OppligerDouglas, and G. Anzalone, "The RepRap 3-D Printer Revolution in STEM Education," in 121st asee annual conference \& exposition., 2014.

[39] J. M. Pearce, "Impacts of open source hardware in science and engineering," Bridge, vol. 47, no. 3, pp. 24-31, 2017.

[40] J. Menold, K. Jablokow, and T. Simpson, "Prototype for X (PFX): A holistic framework for structuring prototyping methods to support engineering design," Design Studies, vol. 50, pp. 70-112, 2017, doi: 10.1016/j.destud.2017.03.001. 